\title{
Effect of Meteorological Parameters on PM10 Concentrations in Ardahan by Wavelet Coherence Analysis
}

\author{
Necla $\operatorname{Barl}_{1} \mathrm{k}^{*}$ (iD) \\ ${ }^{1}$ Ardahan University, Engineering Faculty, Department of Environmental Engineering, 75002 Ardahan, Turkey \\ *neclabarlik@ardahan.edu.tr \\ * Orcid: 0000-0003-0000-1903
}

Received: 17 May 2020

Accepted: 4 March 2021

DOI: $10.18466 /$ cbayarfbe. 738596

\begin{abstract}
In the city of Ardahan, the PM10 concentrations are high especially in winter and autumn due to heating in buildings. This paper investigates the impact of meteorological parameters (air temperature, air pressure, humidity and wind speed) on the PM10 concentrations in the city of Ardahan by using the Wavelet Coherence analysis. The data have been provided from the records of the Ministry of Environment and Urbanization Continuous Monitoring Center and the Turkish State Meteorological Service in between 2010-2020. The results of the study show that selected meteorological parameters have the different effects on the PM10 concentrations in a period of ten years. Wavelet coherence approach presents clearly the influence of meteorological factors on the PM10 concentrations, and the approach is quite useful in terms of the practical explanation of available data, also.
\end{abstract}

Keywords: Meteorological parameters, PM10, time series, wavelet coherence

\section{Introduction}

As world population increases, the share of particulate matter (PM) concentrations in air pollution problems in urban centers also increases. PM is a general term used to classify air pollutants containing air-suspended particles, varying in composition and size, resulting from various natural or anthropogenic activities. Anthropogenic origin PM emissions emitted from motor vehicles, electricity generation, industrial facilities and domestic heating sources. The coarse, particulate matter with aerodynamic diameters from $2.5 \mu \mathrm{m}$ to $10 \mu \mathrm{m}$ is classified as PM10 [1, 2].

Many studies have shown that there is a close relationship between PM10 pollution and human health deterioration [2, 3, 4]. For this reason, national and international organizations set limit values for different exposure times, taking into account the observed health effects. In the regulations of the EEA (European Environment Agency) and WHO (World Health Organization), the daily average limit values for PM10 are $50 \mu \mathrm{g} / \mathrm{m}^{3}$. This value is $70 \mu \mathrm{g} / \mathrm{m}^{3}$ for our country.

Better understanding of spatial and temporal variability of pollutant concentrations in the atmosphere is seen as an important component of air quality management and health risk assessment. Low air quality and pollution events in any location are affected by a wide variety of factors such as pollutant emissions, meteorology and topography. Therefore, it is important to analyze pollutant concentrations in relation to these factors [5]. Many researchers were investigated influence of temperature, relative humidity, precipitation, air pressure and wind speed (or direction) on concentrations or pollution index of PM10 by using approaches such as basic statistical calculates [6], correlation [7], regression models [8, 9], Fourier transform [10], wavelet transform [11, 12] and neural networks [13] as spatially and temporally. Generally, temperature, relative humidity, precipitation and wind speed have correlated negative correlation with the PM10 concentration and air quality index (AQI), and positive correlation with daily temperature range and atmospheric pressure PM10 and AQI.

This paper analyzes the impact of meteorological variables such as air temperature, air pressure, humidity and wind speed to the concentration of PM10 in the city of Ardahan by using a linear regression and the Wavelet Coherence approach (WTC). Linear regression was used as a tool for basic analysis and relative comparison. 
Wavelet transform is the improved version of Fourier transform. This analysis can be performed in several ways, a continuous wavelet transforms and a discrete wavelet transforms. The fields of application vary from science, engineering, medicine to finance such as wave propagation, data compression, signal processing, image processing, pattern recognition, computer graphics, the detection of aircraft and submarines, cell membrane recognition, blood pressure, heart rate, ECG analyses, internet traffic description and weather data etc. The application of wavelet analysis becomes more widely spread as the analysis technique becomes more generally known [14].

\section{Materials and Methods}

Ardahan is a small city located north east region of Turkey. In the city, which is $1829 \mathrm{~m}$ above sea level, the city's continental climate prevails. Winters are long, hard and snowy. The annual average temperature of Ardahan is $5^{\circ} \mathrm{C}$. For this reason, the heating in the houses is carried out for about eight months.

\subsection{The Data}

In the city, there is a monitoring station of the Ministry of Environment and Urbanization Continuous Monitoring Center. PM10 hourly values of the 10 - year period, covering 2010 - 2020, were saved online from the measurements of the station [15]. Meteorological parameters such as temperature, humidity, pressure and wind speed were requested from the Turkish State Meteorological Service. Following analyzes were used 24-hour average values of the data.

\subsection{Methodology}

To analyze the relationship between the meteorological parameters and the PM10 concentrations a linear regression and WTC analysis have been performed. Regression analysis estimates potential relationship between two variables and mathematical description of this analysis is known well in literature. It was used as a tool for basic analysis and relative comparison, in here.

$$
y(t)=m x(t)+n
$$

where $\mathrm{m}$ and $\mathrm{n}$ are the regression coefficients, $\mathrm{x}(\mathrm{t})$ represents the time series of the meteorological parameters such as air temperature, air pressure, relative humidity and wind speed and $\mathrm{y}(\mathrm{t})$ represents the time series of PM10 for this study. For determination of the representation of the regression model is used a coefficient of $r$-square $\left(r^{2}\right)$ which ranges from 0 to 1 . As the coefficient approaches 1 , the representation ability of the regression model increases.

WTC has been performed as the second methodological approach. A wavelet function is used in wavelet transform. The wavelet transform is conducted by shifting $(\tau)$ and scaling (s) the mother wavelet $(\psi)$ across the time series $(x)$ as a function of time $(x(t))$. The definition of a continuous wavelet (CWT) is $[16,17]$ :

$$
W_{x, \Psi}(\tau, s)=\int_{-\infty}^{+\infty} x(t) \frac{1}{\sqrt{s}} \psi^{*}\left(\frac{t-\tau}{s}\right) d t
$$

where $*$ denotes the conjugate complex value.

Morlet wavelet is mostly preferred in applications since it is similar to normal distribution curve. Morlet wavelet, is given by [18]:

$$
\psi(\mathrm{t})=\pi^{-1 / 4} e^{i \omega_{0} t} e^{-t^{2} / 2}
$$

where $\pi^{-1 / 4}$ and $\omega_{0}$ are a normalization factor and a dimensionless frequency parameter, respectively

Wavelet coherence (WTC) can be explained the time and frequency components as well as the strength of correlation between the time series in the timefrequency space [19]. Therefore, the wavelet coherence can be supplies a better correlation between the meteorological parameters and the PM10 concentrations in comparison with the conventional correlation analysis. Following the WTC is defined as [16]:

$$
R_{x, y}^{2}(\tau, s)=\frac{\left|S\left(s^{-1} W_{x, y}(\tau, s)\right)\right|^{2}}{S\left(s^{-1}\left|W_{x}(\tau, s)\right|^{2}\right) S\left(s^{-1}\left|W_{y}(\tau, s)\right|^{2}\right)}
$$

where $\mathrm{S}$ is a smoothing operator for performing timefrequency normalization processing and the squared of WTC coefficient, $\mathrm{R}^{2}$, is in the following range:

$$
0 \leq R_{n}^{2}(s) \leq 1
$$

If the coefficient equals 1 , there is a perfect linear relation between the $\mathrm{x}(\mathrm{t})$ and $\mathrm{y}(\mathrm{t})$ if it equals 0 , two series are independent. MATLAB codes have been used for wavelet coherence transformation. In wavelet coherence plots, red indicates a strong correlation between meteorological parameter and PM10 concentrations, while blue indicates zero or no correlation between these time series.

The coefficient of wavelet coherence is expressed by the term square, therefore it cannot reveal the difference between positive and negative correlations. Phase difference is used to provide information about backwards and forwards relationships between the two variables. The phase difference $\left(\phi_{\mathrm{x}, \mathrm{y}}\right)$ characterizes the phase relationship between $\mathrm{x}(\mathrm{t})$ and $\mathrm{y}(\mathrm{t})$ [17]:

$$
\phi_{x, y}(\tau, s)=\tan ^{-1}\left(\frac{\Im\left[s\left(s^{-1} W_{x, y}(\tau, s)\right)\right]}{\Re\left[s\left(s^{-1} W_{x, y}(\tau, s)\right)\right]}\right)
$$

where $\mathfrak{I}$ and $\mathfrak{R}$ denote an imaginary and a real operator, respectively. The definition range of $\phi_{\mathrm{x}, \mathrm{y}}$ is $[-\pi, \pi]$. 
If $\phi_{\mathrm{x}, \mathrm{y}} \in(0, \pi / 2)$, then the series moves together positively and $\mathrm{x}(\mathrm{t})$ leads $\mathrm{y}(\mathrm{t})$

If $\phi_{x, y} \in(\pi / 2, \pi)$, then the series moves together negatively and $y(t)$ leads $x(t)$

If $\phi_{x, y} \in(-\pi / 2,0)$, then the series moves and $y(t)$ leads $\mathrm{x}(\mathrm{t})$

If $\phi_{x, y} \in(-\pi, \pi / 2)$, then the series moves and $x(t)$ leads $\mathrm{y}(\mathrm{t})$

\section{Results and Discussion}

Ardahan, Turkey is one of the coldest cities. PM10 concentrations are particularly high in winter and autumn due in buildings to heating. The highest values of the PM10 concentrations have been recorded in January, February and December. Between January 2010 and January 2020, 13 days unhealthy (> 261 $\left.\mu \mathrm{g} / \mathrm{m}^{3}\right)$ and 335 days sensitive $\left(101-260 \mu \mathrm{g} / \mathrm{m}^{3}\right)$ weather conditions were observed according to the average national AQI PM10 values. In approximately $30 \%$ of the period, the PM10 particles concentration is above the 24-hours limit set by WHO.

In this period, the average daily temperature was $5.19^{\circ} \mathrm{C}$, while the hottest day was as $23.50^{\circ} \mathrm{C}$ on August 7, 2017 and the coldest day as $-26.80{ }^{\circ} \mathrm{C}$ on February 4, 2014. Air pressure varied between $800.50-830.60 \mathrm{hPa}$. If about 10-days records between 30.1 to $36.2 \mathrm{~m} / \mathrm{s}$ are excluded in June 2015, the average wind speed has been $1.13 \mathrm{~m} / \mathrm{s}$. The average relative humidity was $68.03 \%$.

There is no any industrial activity in the city. The share of pollution from traffic is also low in total pollution. The biggest natural source that can be shown to the high concentrations of PM10 in the city are the dust from the roads. The main source in terms of anthropogenic effects; are relatively low quality coals used in buildings for heating purposes. The amount of coal used for heating in 2018 was approximately 11 tons and the amount of natural gas was $15000 \mathrm{~m}^{3}$ [20].

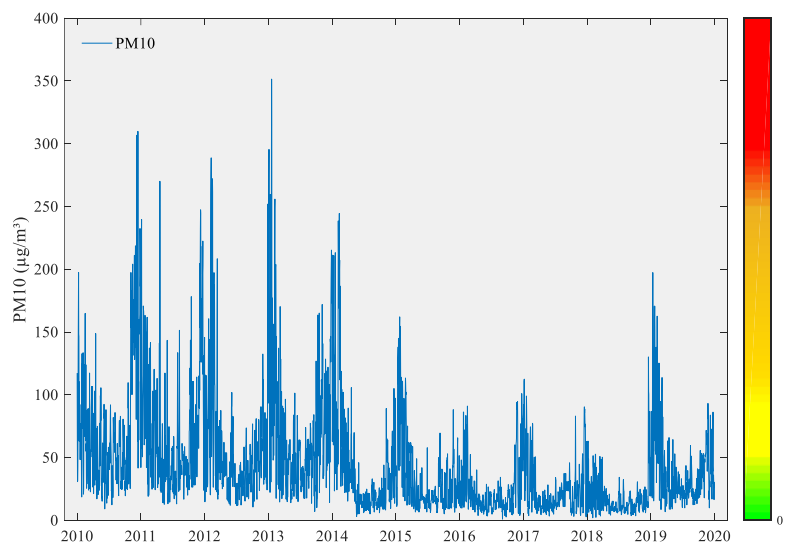

Figure 1. Daily values of the PM10 particle concentration between 2010-2020. The colormap shows the national air quality index (AQI)
Fig. 1 shows the time series of 24 -hour the PM10 concentrations from January 2010 to January 2020.The time series are represented by 3468 sample points. The highest PM10 concentrations have been measured in January 2013 , as $351.5 \mu \mathrm{g} / \mathrm{m}^{3}$. Since 2014 , natural gas has been used in buildings for heating purposes. The decrease in the PM10 particles the concentrations after the use of natural gas is clearly seen in Fig. 1, also. Days exceeding the limit values are mostly seen before this date.

\subsection{Linear Regression Analysis Between the Meteorological factors and the PM10 values}

The linear regression approach was conducted to examine the effect of meteorological factors (air temperature, air pressure, relative humidity and wind speed) on changes in the PM10 concentration. Daily average the values of meteorological parameters and 24hourly average PM10 the concentrations for the period 2010 - 2020 are presented in Fig. 2.

Fig. 3 shows correlations between the meteorological parameters and the PM10 particles concentration, as scatter plot. 10-day excessive wind speed signals, considered as noise, were not included in the analysis. While temperature and wind speed are negatively correlated with the PM10 concentration, air pressure and relative humidity are positive with PM10. The values of calculated the coefficients $\left(r^{2}\right)$ between temperature, air pressure, relative humidity and wind speed and PM10 are: 0.18470, 0.00018, 0.02151 and 0.02376 , respectively. The correlation coefficient is the highest for temperature - PM10 and the lowest for air pressure - PM10.

The results of this study shows that the correlation between the PM10 concentrations and temperature is negative so the low PM10 concentrations has occurred at the high temperatures. In other words, decreased temperature has been associated with an increase in the PM10 concentrations. The relationship observed between wind speed and the PM10 concentrations is similar, also.

According to the results, the low PM10 concentrations have occurred in the low relative humidity rate. In other words, with increased the relative humidity, the concentration has increased as well, but the correlation between the PM10 concentrations and the relative humidity is weak.

Essentially, the time series in Fig. 2 are very useful for practical analysis. It is clearly seen in the time series given in Fig. 2 that the PM10 concentrations decrease as the temperature and wind speed increase. Moreover, increases in wind speed and relative humidity also coincide with increases in the PM concentrations. 

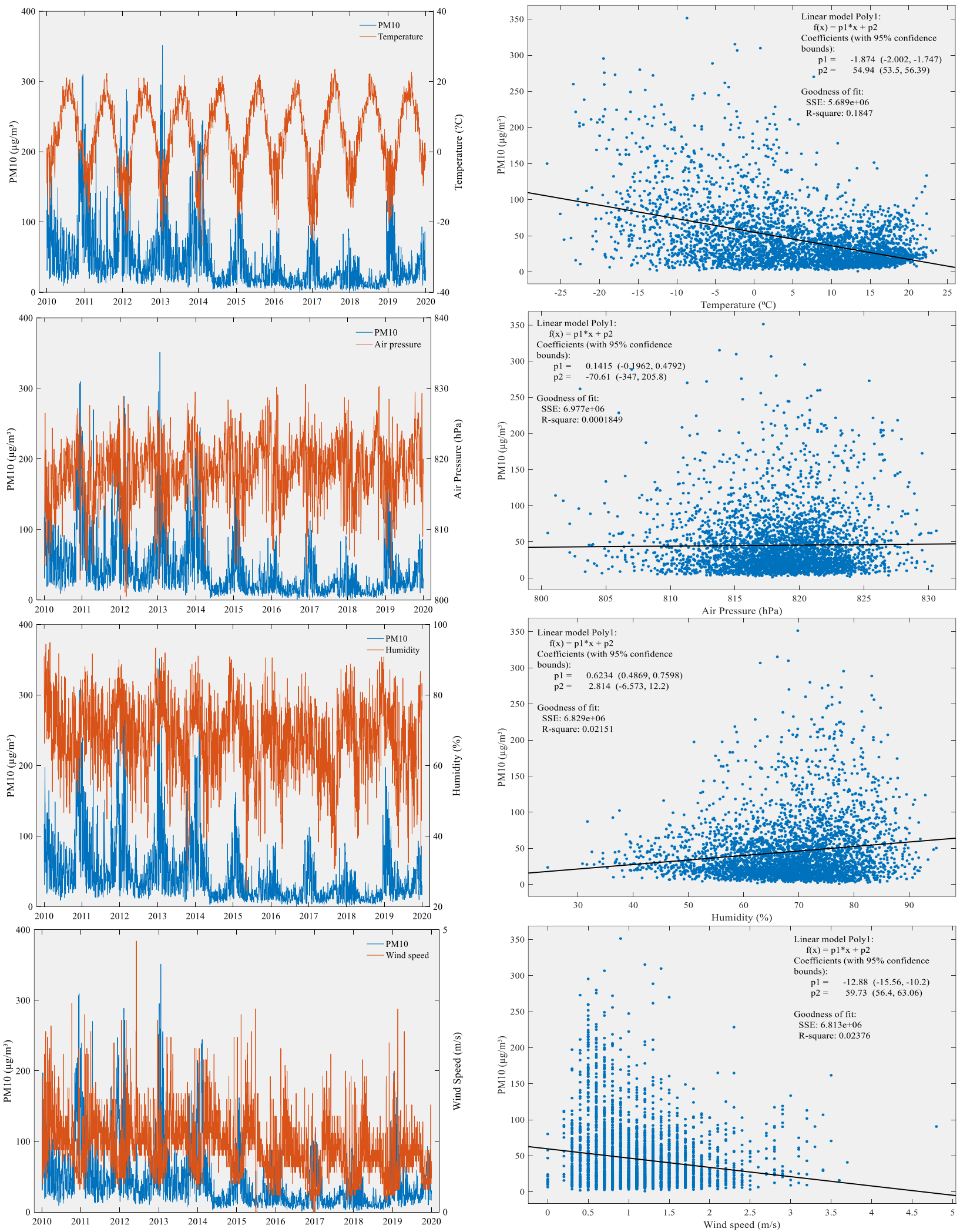

Figure 2. The time series of 24-hour the PM10 concentrations and meteorological parameters (temperature, air pressure, relative humidity and wind speed from top to bottom respectively) in 2010-2020

Figure 3. Correlations between the meteorological parameters (temperature, air pressure, relative humidity and wind speed from top to bottom respectively) and the PM10 concentrations in the period of $2010-2020$ 
However, the results of the regression analysis are not sufficient and strong to reveal the correlation between the time series. The regression statistics given above have a very low regression coefficient, which indicates that it is not appropriate to apply linear regression analysis to large interval time series. Also, as seen in Fig. 2, the PM10 concentration is not expected to be the same throughout the year due to meteorological factors. Detailed regression analysis between daily the PM10 emissions and the meteorological parameters is needed on a monthly scale. Low regression coefficients also require the application of different approaches in the analysis of the time series.

\subsection{Wavelet coherence between the meteorological parameters and PM particles the concentration}

The WTC plots show the regions the time series change together. WTC approach has been applied to show the relationships between the meteorological factors and the concentrations of PM10 in different time-frequency spaces. The phase difference between the time series is indicated by arrows on the graph [21]. The direction of the arrows shows the level and type of correlation in terms of time shifts, while also showing the relative bond between the phenomena.

The results of WTC analysis between the meteorological factors and PM10 the concentrations for the period of $2010-2020$, is presented in Fig. 4. Different WTC ranges are colored emphasizing to the significance of the regions, as from blue to red. This approach not only provides important information about the common behavior of the time series under study, but also gives an interesting idea of the phenomenon under study. In the WTC analysis of the temperature-PM10 series, the first characteristic period is between 4 and 32 days and has been out of phase many times over during observed time interval. In the period between 128 and 256 days, between time series is identified significant the correlation in time interval the end of 2012 and to the early 2014, also with out of phase. For the period about 256 days, the common behaviors of air temperature and PM10 concentration move out of phase during all observed time interval, in other words the correlation between time series is quite significant. This shows the high seasonal dependence between temperature and the PM10 variations. This is especially obvious in the days around new year's 2013-2014, 2014-2015, 2015-2016, 2016-2017 and 2017-2018.

According to WTC analysis applied between air pressure and PM10 the first characteristic period is between 32 and 64 days and has been out of phase time interval new year of 2014 and the end of 2015 and to the early 2017. From 2010 to the end of 2019 the common behaviors of two-series are out of phases for the period about 256 days and there are significant correlations. Also, dynamics of out phase has been seen the period between 16 and 32 days in the winter of 2013 and the period between 32 and 64 days in the winter of 2015 .
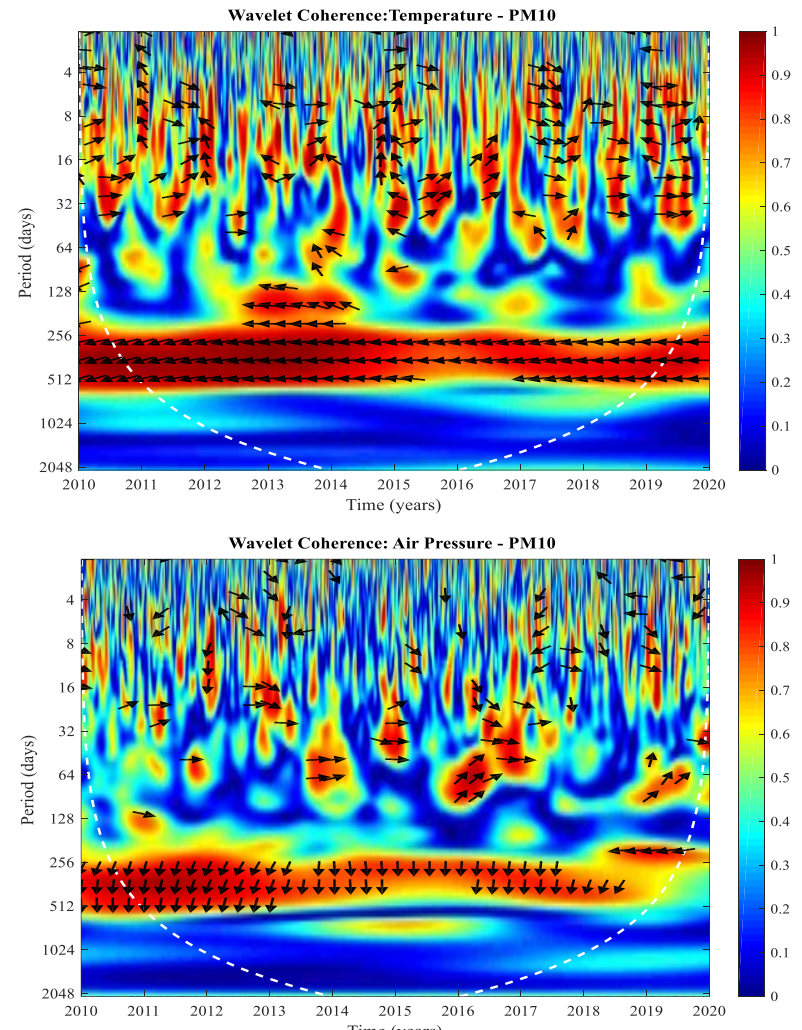

Wavelet Coherence: Humidity - PM10
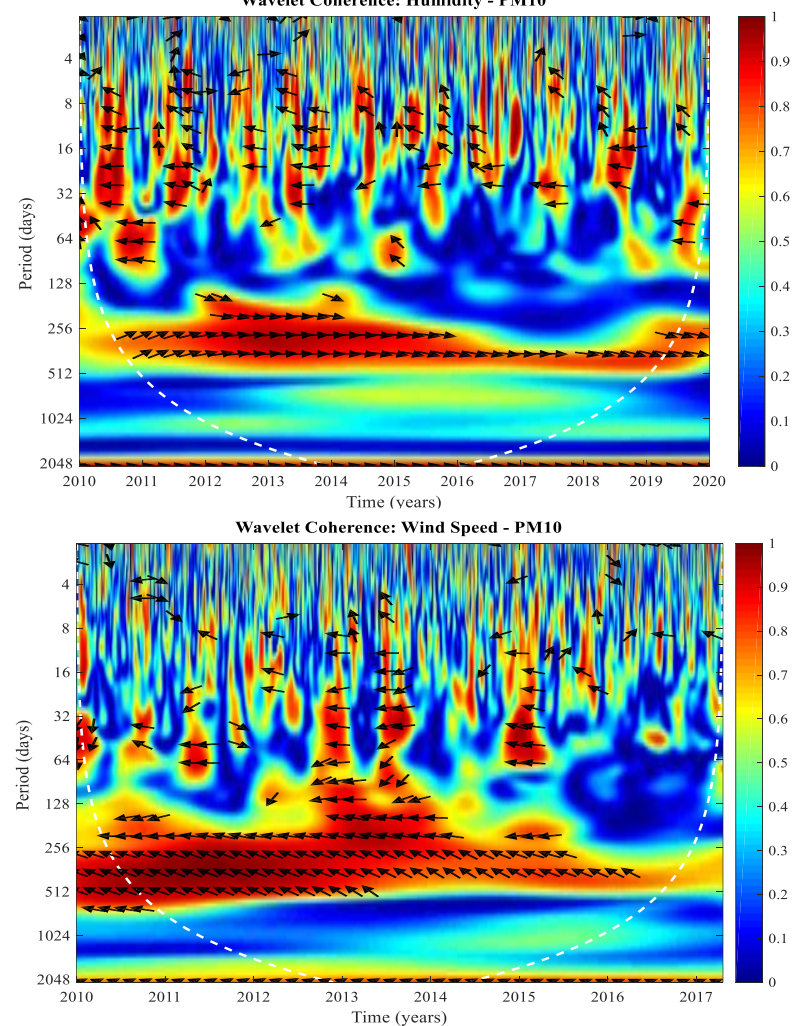

Figure 4. WTC of daily values of the meteorological factors (temperature, air pressure, relative humidity and wind speed from top to bottom respectively) and the PM10 concentrations in the period of 2010 -2020 
For the period about 256 days, the common behaviors of relative humidity-PM10 and wind speed-PM10 move out of phase during all observed time interval such as in the series of air temperature-PM10 and pressure-PM10. In other words, the correlation between these series is significant, also. In the WTC graphic of the series of humidity-PM10 is seen out of phase the period between 8 and 32 days in between 2010 and 2011. This interval, which corresponds to the spring of 2010 indicates the rainy period. Besides, it is seen out of phase the period between 32 and 128 days in the autumn of 2011, indicates the snowy period. This case is especially evident in the days around the autumn periods for the whole of the studied time interval. In the WTC graphic of the series of wind speed-PM10 is seen out of phase in the period between 16 and 64 days both in the end of 2013 and new year's 2013 and 2014, in other words the correlation between time series is significant.

The common behaviors of between the meteorological factors and the PM10 move out of phase for the period about 256 days during all observed time interval. This is very interesting as the correlation between the series indicates positive and significant trend in about 256 days band. Again, in this period, the distribution of colors towards lighter red after 2015 (after the use of natural gas becomes widespread) is another interesting result, also.

\section{Conclusion}

In this paper, the influence of meteorological factors on the PM10 concentration in the period 2010-2020 in Ardahan has been analyzed by using the WTC approach.

According to records that are saved from monitoring stations of the Ministry of Environment and Urbanization Continuous Monitoring Center in Ardahan, the PM10 concentrations were seasonally high, especially in autumn and winter. The use of natural gas for heating in buildings has have a significant impact on the reduction of the PM10 concentrations in the city. According to the air quality index, all of the unhealthy $\left(>261 \mu \mathrm{g} / \mathrm{m}^{3}\right)$ weather conditions and a very important part of the sensitive $\left(101-260 \mu \mathrm{g} / \mathrm{m}^{3}\right)$ weather conditions in the city has been recorded before the use of natural gas.

Meteorological conditions corresponding to the high values of PM10 concentrations have appeared in the scatter plot between time series. These values have varied in the following ranges: the air temperature values from $-25^{\circ} \mathrm{C}$ to $+5^{\circ} \mathrm{C}$, the air pressure values from 810 to $825 \mathrm{hPa}$, the values of relative humidity from 65 to $85 \%$ and wind speed from 0.5 to $1.5 \mathrm{~m} / \mathrm{s}$. The linear regressions between the time series show the PM10 concentrations sensitivity to meteorological conditions. However, regression statistics are characterized by a very low coefficient of determination, indicating that it has the potential to discover other alternative approaches.

The WTC approach applied in this research not only allows a time-frequency analysis of the time series, but also helps to identify time frames where a significant correlation between the meteorological factors and the PM10 concentrations can be expected. Also, unlike linear regression, WTC analysis shows that a larger number of examples provide a better and more detailed analysis of the phenomenon studied, providing more information about the dynamic behavior and relationships of the time series.

In this study, periods in which meteorological variables have a significant effect on the PM10 concentrations were determined. From the WTC analysis it has been seen possible to produce useful results for a better understanding of meteorological conditions leading to increase the PM10 concentrations.

\section{Acknowledgement}

Thanks the Turkish State Meteorological Service as it supports the performing of the study by sharing meteorological parameters.

\section{Author's Contributions}

Necla Barlık: Drafted and wrote the manuscript, performed the experiment and result analysis.

\section{Ethics}

There are no ethical issues after the publication of this manuscript.

\section{References}

1. Miller, BG. Clean Coal Engineering Technology; 2nd Edition, Elsevier Inc.: Pennsylvania, US, 2017; pp. 419-420

2. Cheng, Z, Jiang, J, Fajardo, O, Wang, S and Hao, J. 2013. Characteristics and health impacts of particulate matter pollution in China (2001-2011). Atmospheric Environment; 65:186-194.

3. Kappos AD, Bruckmann P, Eikmann T, Englert N, Uwe H, Höppe P, Koch E, Krause GH, Kreyling WG, Rauchfuss K, Rombout P, Schulz-Klemp V, Thiel WR and Wichmann HE. 2004. Health effects of particles in ambient air. International Journal of Hygiene and Environmental Health; 207(4):399-407.

4. Wilson JG, Kingham S, Pearce J and Sturman AP. 2005. A review of intraurban variations in particulate air pollution: Implications for epidemiological research. Atmospheric Environment; 39: 6444-6462.

5. Ştefan, S, Radu C and Belegante, L. 2013. Analysis of Air Quality In Two Sites With Different Local Conditions. Environmental Engineering and Management Journal; 12(2):371-379.

6. Guerra, SA, Lane, DD, Marotz, GA, Carter, RE, Hol CM and Baldauf, RW. 2006. Effects of Wind Direction on Coarse and Fine Particulate Matter Concentrations in Southeast Kansas. Journal of the Air \& Waste Management Association; 56:1525-1531.

7. Galindo, N, Varea, M, Gil-Moltó J and Yubero, E. 2011. The 
Influence of Meteorology on Particulate Matter Concentrations at an Urban Mediterranean Location. Water Air and Soil Pollution 2015: 365-372.

8. Bathmanabhan, S and Madanayak, SNS. 2010. Analysis and interpretation of particulate matter - PM10, PM2.5 and PM1 emissions from the heterogeneous traffic near an urban roadway. Atmospheric Pollution Research; 1:184-194.

9. Sajjadi, SA, Zolfagharib, G, Adab, H, Allahabadi A and Delsouza, M. 2017. Measurement and modeling of particulate matter concentrations: Applying spatial analysis and regression techniques to assess air quality. MethodsX; 4:372-390.

10. Tchepel, O and Borrego, C. 2010. Frequency analysis of air quality time series for traffic related pollutants. Journal of Environmental Monitoring; 12: 544-550.

11. Li, L, Qian, J, Ou, CQ, Zhou, YX, Guo, C and Guo, Y. 2014. Spatial and temporal analysis of Air Pollution Index and its timescale-dependent relationship with meteorological factors in Guangzhou, China, 2001-2011. Environmental Pollution; 190:7581.

12. Anusasananan, P. 2019. Wavelet spectrum analysis of PM10 data in Bangkok, Thailand. Journal of Physics: Conference Series, 1380:1-9.

13. Biancofiore, F, Busilacchio, M, Verdecchia, M, Tomassetti, B, Aruffo, E, Bianco, S, Tommaso, SD, Colangeli, C, Rosatelli G and Carlo, PD. 2017. Recursive neural network model for analysis and forecast of PM10 and PM2.5. Atmospheric Pollution Research; 8(4): 652-659.

14. Sifuzzaman, M, Islam, MR and Ali, MZ. 2009. Application of Wavelet Transform and its Advantages Compared to Fourier Transform. Journal of Physical Sciences; 13:121-134.

15. Environment and Urban Ministry, Hava Kalitesi Veri Bankası. http://www.havaizleme.gov.tr/ (accessed at: 05.05. 2020).

16. Torrence, C and Compo, GP. 1998. A practical guide to wavelet analysis. Bulletin of the American Meteorological Society: 79(1):61-78.

17. Nie, $Y$, Chen, $P$, Zhang, $T$ and Wang, E. Impacts of internationa oil price fluctuations on China's PM2.5 concentrations: a wavelet analysis. 2019. Economic Research-Ekonomska Istrazivanja;1-21.

18. Grossmann, A and Morlet, J. 1984. Decomposition of hardy functions into square integrable wavelets of constant shape. Society for Industrial and Applied Mathematics; 15(4): 723-736.

19. Loh, L. 2013. Co-movement of Asia-pacific with European and us stock market returns: A cross-time-frequency analysis. Research in International Business and Finance; 29:1-13.

20. Environment and Urban Ministry. 2019. Environmental Status Report for Ardahan 2018 (Turkish).

21. Aguiar-Conraria, L, Azevedo N and Soares, MJ. 2008. Using wavelets to decompose the time-frequency effects of monetary policy. Physica A; 387: 2863-2878. 